\title{
Choperer Historical Perspectives on Mental 5 Health and Psychiatry
}

\author{
Joanna Bourke
}

\section{Introduction}

Robairt Clough was a long-term patient at Holywell Psychiatric Hospital in Antrim (Northern Ireland). In the Christmas 1972 edition of the patients' magazine, he wrote the following verses:

$$
\begin{aligned}
& \text { Little drops of medicine, } \\
& \text { Little coloured pills, } \\
& \text { Cure us of all ailments, } \\
& \text { Cure us of all ills. }
\end{aligned}
$$

Doctors with a stethoscope,

Doctors with a bag,

Make us fit and healthy,

Cheer us when we flag.

Pretty little nurses

Nurses bold and strong,

Nurses with a banjo,

Nurses sing a song.

Wardsmaids with the dinner,

Wardsmaids with the tea,

Keep our tummies happy,

Until the day we're free. ${ }^{1}$

This little ditty from 1972 draws attention to some of the dominant themes in the social history of mental health and psychiatry in Britain from the 1960s to the 2010s. These include the championing of psychopharmacology (those 'little coloured pills'), symbolic representations of psychiatric authority (stethoscope and medicine bag), the emotional management of patients ('pretty little nurses' with their songs), cultures of conviviality (keeping tummies happy) and, of course, the ominous mood instilled by disciplinary practices and environments (they wait 'Until the day we're free'). The ditty acknowledges the social meanings generated when psychiatric patients and health professionals meet. Each participant brings to the encounter a multitude of identities based on gender, class, ethnicity, sexuality, generation, age, religion and ideological dogmas as well as memories of past encounters, sensual perceptions and embodied knowledges. As a result, any overview of the history of British psychiatry needs to grapple with the tension between temporally fluid societal contexts and the sensual intimacy of very personal human 
encounters (i.e. seeing the Other, touching, stories only partly heard, bodily smells, the metallic taste of pills).

The historiographical literature on mental health and psychiatry from the 1960s to the end of the first decade of the twenty-first century is exceptionally detailed in terms of policy and politics. Scholars have drawn on Foucault's 'great confinement' (particularly his book Madness and Civilization), Roy Porter's patients' perspectives, material culture and the powerful themes of discipline, power and social construction. ${ }^{2}$ In contrast to these grand political and theoretical themes, this chapter seeks to explore some of the most significant changes in the lived experiences of mental health and psychiatry. It pays attention to social encounters between medical professionals and patients.

It is important to acknowledge, however, that the medical professionals discussed in this chapter are not the main caregivers. People identified as having 'mental health issues' engage in their own practices of self-care. They often have strong familial networks (especially those sustained by mothers, grandmothers, daughters and sisters). They routinely seek advice from health-oriented journalists, radio and television programmers, teachers, police, pharmacists and doctors' receptionists, not to mention herbalists, tarot card readers, astrologers, psychics and faith healers. Since the 1960s, Britain has undoubtedly become more secular, but distressed people continue to seek the laying on of hands. As I argue in my book The Story of Pain: From Prayer to Painkillers, secularisation is honoured more in rhetoric than reality. ${ }^{3}$ The same people who attend consultations with cognitive behavioural therapy (CBT) therapists eventually return home where they call out to their gods for relief of mental suffering.

Psychiatric professionals, however, claim to provide a superior tier of help to people who identify themselves, or are identified by others, as experiencing mental health problems. In the period from the 1960 s to 2010 , there are six major shifts in encounters between these professionals and their patients: deinstitutionalisation, changes in diagnostic nomenclature, anti-psychiatry, patients' movements, evidence-based medicine and the privileging of psychopharmacology, neurochemistry and neurobiology. These themes overlap to varying degrees.

\section{Deinstitutionalisation}

The first theme is deinstitutionalisation (see also Chapter 31). The closure of the Victorian public asylum system and its replacement with community-based psychiatric services is the greatest social shift for patients and professionals since the 1960s. Although the movement had a long history and was by no means confined to Britain, a decisive moment for British practices occurred in 1961 when Enoch Powell, the minister of health, gave a speech at the annual conference of the National Association for Mental Health (now called Mind). In it, Powell predicted that, within fifteen years, 'there may well be needed not more than half as many places in hospitals for mental illness as there are today'. He described the Victorian asylums as standing 'isolated, majestic, imperious, brooded over by the gigantic water-tower and chimney combined, rising unmistakable and daunting out of the countryside'. These asylums 'which our forefathers built with such immense solidity to express the notions of their day' were now outdated. He maintained that it was necessary for 'the medical profession outside the hospital service ... to accept responsibility for more and more of that care of patients which today is given inside the hospitals'. They had to be 'supported in their task' by local authorities. ${ }^{4}$ In the years that followed Powell's speech, mentally ill people moved 
repeatedly between hospitals, care centres, other local facilities and family homes, as well as within a growing sector of 'for-profit' care. The belief that welfare dependency was obsolete and morally corrupting grew; the mentally ill were not only encouraged but required to become independent and autonomous.

Deinstitutionalisation had major societal effects. Attacks on the welfare state by the governments of Margaret Thatcher and John Major contributed to the stigmatisation of the poor and mentally ill. Asylums were emptied and converted into luxury homes, parks and other public centres. In the 1950s, there were 150,000 psychiatric beds in England; by 2006, this had fallen to $34,000 .^{5}$ The underfunding of mental health services, especially when compared to physical health facilities, plagues the entire field. ${ }^{6}$

The emergence of therapeutic communities in the 1950s led by Maxwell Jones encouraged other psychiatrists such as John Wing, director of the Medical Research Council's Social Psychiatry Research Unit between 1965 and 1989, to propagate the concept of 'rehabilitation'. Prior to this period, 'rehabilitation' had primarily referred to assistance to people who were physically injured, especially ex-servicemen, but it was reworked as a way of providing mentally unwell patients with the skills necessary for independent living. ${ }^{7}$ Prescriptions for drugs skyrocketed. Prisons, too, had to deal with soaring numbers of inmates diagnosed with mental illnesses, although it is unclear if this was due to the 'psychiatrisation' of criminality or a greater recognition of mental illness more generally. ${ }^{8}$

There is no consensus about whether deinstitutionalisation has been a good or bad thing. Was it an enlightened move, facilitated by the introduction of more effective drugs and seeking to give greater autonomy to the mentally ill? Or was it a component of rightwing policies determined to slash public spending, irrespective of the effects on vulnerable members of society?

Few commentators, though, dispute the fact that deinstitutionalisation did create many new problems. A lot of people who needed support lost contact with mental health services altogether. ${ }^{9}$ There was often inadequate or non-existent community provision in the first place. After all, in 1959, there were only twenty-four full-time psychiatric social workers employed by local authorities throughout England. This problem was exacerbated by the balance-of-payment crisis and inflation in the 1970s, which left local authorities struggling to cope ${ }^{10}$ Even Frank Dobson, secretary of state for health between 1997 and 1999, admitted that 'care in the community has failed'. He observed that

people who are mentally ill, their carers and the professional staff responsible for their welfare have suffered from ineffective practices, an outdated legal framework and lack of resources... Discharging people from institutions has brought benefits to some. But it has left many vulnerable patients to try to cope on their own ... Too many confused and sick people have been left wandering the streets and sleeping rough. ${ }^{11}$

Deinstitutionalisation was a particular problem for the most severely and chronically ill who required long-term care. One group that was most ruthlessly affected was older people. They often suffer from complex, overlapping psychiatric conditions, including disorders such as depression, chronic degenerative brain disorders and lifestyle crises resulting from isolation and bereavement. ${ }^{12}$ Despite this, mentally ill older people were relegated to a lowly position within the hierarchy of psychiatry patients. As late as the 1940s, there were no specialist services in England for people with senile dementia. ${ }^{13}$ The first international conference on the subject only took place in London in $1965 .{ }^{14}$ Even at the end of the 1970s, only half of health service districts provided specialist services for older people with mental 
health issues. ${ }^{15}$ Older men and women were increasingly and disproportionately represented in psychiatric institutions. For example, in the early 1970s, around 9 per cent of the population of England and Wales were over sixty-five years of age, but they occupied 47 per cent of the psychiatric beds. ${ }^{16}$ In the words of the psychiatrist W. Alwyn Lishman, who worked in the late 1950s,

Every large mental hospital has a secret large ward tucked away - perhaps three or four ... which were not much visited because they were full of old demented people. Because there was no interest in them, it fell to the most junior doctor to go there once a week to see if any one needed to have their chest listened to. The most neglected parts of any mental hospital were the old age wards. ${ }^{17}$

Deinstitutionalisation and 'community care' made these older patients' situation even worse (see also Chapter 22). Families struggled to cope. Despite the obvious dependence of older people on the state, little investment was forthcoming. Ageism and prejudiced beliefs that nothing could be done to improve their well-being hampered positive responses. In 1973, J. A. Whitehead, consultant psychiatrist at Bevendean Hospital in Brighton, bluntly declared that psychiatric services were 'loath to deal with [older] patients'. He added that, when this neglect was 'coupled with society's fear of mental illness and the ambivalent attitudes to older people in general, the mentally ill old person is in a dismal position'. ${ }^{18}$

\section{Anti-psychiatry}

If the first theme is deinstitutionalisation, with its negative effects on the most vulnerable members of society, including older people, the second is anti-psychiatry (see also Chapter 20). Although the German physician Bernhard Beyer first used the term 'anti-psychiatry' in 1912, David Graham Cooper (a South African psychiatrist who trained and worked in London) popularised it in his book Psychiatry and Anti-Psychiatry (1967). In it, Cooper accused psychiatry of being in danger of committing a well-intentioned act of betrayal of those members of society who have been ejected into the psychiatric situation as patients'. ${ }^{19}$ The movement was led by global figures such as Michel Foucault, Erving Goffman, Ken Kesey and Thomas Szasz and, in Britain, by R. D. Laing, Cooper and, from 1966, the Institute of Phenomenological Studies. ${ }^{20}$ These anti-psychiatrists were embedded in wider countercultural movements. They maintained political links with global liberationist movements and were attracted by existential psychiatry and phenomenology.

They were a diverse group but all rejected the 'whiggish' approach to psychiatry - that is, the 'rise and rise' of psychiatric knowledge and power. Instead, they developed damning critiques of the profession, arguing that it was damaging people's lives. As Laing explained in The Voice of Experience (1982), asylums were total institutions, like concentration camps. When patients enter psychiatric care, he contended, they 'are mentally dismembered. Raw data go into the machine, as once raw human meat into the mouth of Moloch' (i.e. the Canaanite god associated with child sacrifice). ${ }^{21}$

For anti-psychiatrists, society not biology was the cause of mental distress. Laing's highly influential work on schizophrenia strengthened their belief that even major disturbances could be understood as intelligible responses to environments and relationships. Both Laing and Cooper were also highly critical of the bourgeois family, warning that it fostered psychic abuse. For many anti-psychiatrists, mental illness did not even exist. As the scholar Michael 
Staub explains in Madness Is Civilization (2018), anti-psychiatrists believed that only 'good fortune and chance' stood between insanity and mental health. ${ }^{22}$

Anti-psychiatrists insisted that mental health could be better achieved by the establishment of therapeutic communities (such as Cooper's Shenley Hospital for young schizophrenics between 1962 and 1967) that were anti-hierarchical, people-led, positive and open to the worlds of psychotics. Laing even argued that severe psychotic illnesses could be healing, enabling a person to travel into a mystical world and return with greater insight. He established the Kingsley Hall therapeutic community for people with psychotic afflictions in 1965 , eradicating hierarchies between patients and doctors. ${ }^{23}$

The long-term assessment of anti-psychiatry is divided. The movement drew attention to abuses of power and the need to give people control over their own lives. Yet, as the historian Andrew Scull concluded, it also encouraged two views. The first was the 'romantic notion' that madness was nothing more than a 'social construction, a consequence of arbitrary labeling'. The second was that 'existing mental hospitals were so awful that any alternative must somehow represent an improvement. Sadly, "it just ain't so". 24

However, anti-psychiatry gained support from a wide range of people who were becoming critical of what was increasingly seen as the abuse of power by psychiatrists. Lobotomy, insulin coma therapy, drug-induced convulsions and electroconvulsive therapy (ECT) treatments were dubbed instruments of oppression, designed not to heal but to coerce people into behaving in particular ways. The treatment of homosexuals was exposed as particularly repellent. Not only were homosexuals given religious counselling and psychoanalysis in an attempt to 'cure' them of their sexual orientation but they were also prescribed oestrogen treatments to reduce libido, ${ }^{25}$ and between the early 1960 s and the early 1970 s, they were subjected to behavioural aversion therapy with electric shocks. Many were given apomorphine (which causes severe nausea and vomiting) as an aversive stimulus (see also Chapter 34). ${ }^{26}$

Revelations of psychiatric abuses swung support behind anti-psychiatrists. Particularly important were Barbara Robb's Sans Everything: A Case to Answer (1967); a 1968 World in Action documentary; reports that ECT was being given without anaesthetic or muscle relaxant at Broadmoor Hospital; and exposés of abuses at Ely (1969), Farleigh (1971), Whittingham (1972), Napsbury (1973), South Ockendon (1974) and Normansfield (1978) hospitals. One of the consequences of the earlier scandals was the setting up of the Health Service Commissioner (Ombudsman) in 1972. Dr Louise Hide discusses these scandals in Chapter 7 in this volume.

\section{Patients' Movements}

Scandals, coupled with rising numbers of voluntary patients (who had been admitted to mental hospitals from 1930), resulted in the third major shift in the social history of mental health and psychiatry in Britain after the 1960s. This was the rise of parents' and then patients' movements (see also Chapters 13 and 14).

There was a range of reasons for the frustration felt by people being treated for psychiatric ailments but the dominant one was linked to debates about informed consent. The 1959 Mental Health Act had not even mentioned consent to treatment. By the early 1970s, the Medical Defence Union endorsed the need for consent but there was a lack of clarity about how medical professionals were expected to ensure that their patients understood the nature, purpose and risks of treatments. ${ }^{27}$ 
By the 1983 Mental Health Act (England and Wales), however, consent was a prominent feature. Part of the credit for this change goes to the rise and growing influence of mental health charities and activist groups, including the National Association for Mental Health (now Mind). When it was established in 1946, Mind brought together professionals, relatives and volunteers to lobby for the improved care of children and adults with psychiatric problems. There was also an abundance of other user-movements, including the Mental Patients' Union, the Community Organisation for Psychiatric Emergencies, Protection for the Rights of Mental Patients in Treatment, Campaign Against Psychiatric Oppression, Survivors Speak Out and the United Kingdom Advocacy Network. Other groups, styling themselves (initially) as charities included the National Autistic Society, which sought to draw the public's attention to the specific needs of autistic children, while also castigating the medical establishment for stigmatising them. From only a dozen such organisations in the 1980 s, there were more than 500 by 2005 , partly due to the establishment of the NHS and the Community Care Act of $1990 .^{28}$ By banding together, the families of people designated 'mentally ill' could share information, provide encouragement and lobby for improved facilities. ${ }^{29}$ In 1970, a major battle was won when the government passed the Education (Handicapped Children) Act, which gave all children with disabilities the right to education.

From the 1970s, activists began drawing on the language of human rights to make their case. In contrast to parents' movements, which tended to lobby for more and better biomedical research into the causes and cures of mental illness, an abundance of patientled organisations sprang up. These groups repudiated the paternalism inherent in charity status, together with the implication that they needed to be 'cured'. As patients, they insisted that they were the ones with the authority to adjudicate on the meaning of their situation and the appropriate responses (which may or may not include treatment). They emphasised health rather than illness. ${ }^{30}$ These patients' movements sought to draw attention to the positive aspects of being 'different'; they insisted on the complexity of their lives; and they reminded people of the contributions they made to society. ${ }^{31}$

Patients' movements were encouraged by the rise of the Internet, which enabled people with mental health problems to communicate with each other much more easily. Mental health blogging greatly facilitated the development of therapeutic communities outside institutional ones. Unfortunately, the positive aspects of these forms of communications have also been exploited by unscrupulous commercial companies, quacks and advertisers.

In more recent decades, the 'rights' discourse has been supplanted by one emphasising individual 'choice'. As the historian Alex Mold boldly states, patients 'have been made into consumers', in which the main language is choice and autonomy. ${ }^{32}$ The Labour government from 1997 to 2010 transformed the NHS into a 'market', which unfortunately has exacerbated inequalities based on race, region, class, gender and age (see also Chapters 3, 10 and 11). Mold concludes that 'It is difficult to see how patient-consumers can overcome completely the power imbalance with health professionals' and 'the tension between individual demands and collective needs also persists. ${ }^{33}$

\section{Diagnostic Nomenclature}

The fourth shift involves the fabrication as well as demolition of diagnostic categories. These processes provide important insights into how knowledge is created, spread, consolidated and shrunk (see also Chapter 17). 
There have always been dramatic shifts in medical nomenclature, the most written about one being the rise of hysteria as a diagnostic category in the Victorian period and then its falling from grace in the twentieth century, as documented by Mark Micale. ${ }^{34}$ In the period from the 1960s to the 2010, the most notable change has been the 1973 removal of homosexuality from the category of a mental illness (although transsexuality has been introduced as an item of interest to psychiatrists).

Another new diagnostic category that has been introduced is attention deficit hyperactivity disorder. It has proved controversial, however, on the grounds that it pathologises children and leads to over-medicalisation. These critiques were linked to wider debates about the 'medicalisation' of everyday problems. Social anxiety disorder, for example, has been said to be an example of medicalising shyness, giving rise to the 'therapeutic state' that psychologises every aspect of people's lives and is inherently pathologising. There has also been the growth of transcultural psychiatry, recognising that diagnostic categories, symptoms and measuring instruments might not be valid for the twenty-two different ethnic groups with populations of more than 100,000 living in the UK (see also Chapters 35 and $36) .^{35}$

\section{Evidence-Based Medicine}

The fifth shift is more administrative but had a major impact on patients and mental health professionals. This is the revolution in evidence-based medicine, with the standardisation of evaluation methods, as well as the formalisation of quality assurance, efficiency metrics, interdisciplinary teams and randomised controlled trials (see also Chapter 17). ${ }^{36}$ In the 1960s, drug trials had simply meant clinical observations. As one psychiatrist involved in early trials of drugs for schizophrenia recalled,

There was no blinding and no randomization. Informed consent was unnecessary. There were no institutional review boards. Initially, there were no rating scales, and results were reported in a narrative fashion. ${ }^{37}$

This all was swept away. As Ann Donald in an article in Culture, Medicine, and Psychiatry argues, one result was the introduction of 'algorithms of care' or 'Wal-Marting'. Instead of individualised, personalised treatments, physicians turn to population-based databases. This 'epistemological change results in the development of a clinical knowledge patterned along algorithmic pathways', Donald explains, 'rather than subjective understanding. An increased and more rapidly rationalization of psychiatry is the result. ${ }^{38}$

\section{Psychopharmacology, Neurochemistry and Neurobiology}

The final shift is one that has affected each of the five themes discussed in this chapter. Since 1900, psychiatric thought has been divided between what have (in very broad strokes) been called biomedical versus psychosocial models (see also Chapters 4 and 17). Is psychiatric ill health primarily physiological or psychosocial? Of course, in reality, nearly everyone (except some anti-psychiatrists) agree that the answer is 'a bit of both'; the dispute is over the balance of impacts. From the 1960s, however, the neurochemical and neurobiological origins of mental illness were privileged over the psychodynamic and sociological. New pharmaceutical products such as anti-anxiety and anti-depressant compounds have also revolutionised treatments. With 'big pharma' has come the increased role of mental health 
insurance industries. Crucial to this shift was the synthetisation of chlorpromazine (Largactil) in 1952, the 'new wonder drug for psychotic illness' ${ }^{39}$ As G. Tourney observed in 1968 ,

We are in the great age of psychopharmacology, in which industry has great stakes ... The physician has become increasingly dependent on brochures from drug companies rather than formal scientific reports. ${ }^{40}$

Freudian therapies, in particular, were stripped from medical training as well as practice. In the words of one commentator, the last half of the twentieth century saw the 'disappearance of the couch'; the Freudian fifty minutes of therapeutic time has been cut to only fifteen minutes of CBT. ${ }^{41}$

Psychopharmacology has been boosted by a massive investment of capital in neurology, other brain sciences and chemistry. The prominent neuropsychiatrist Henry A. Nasrallah argues that the 'future of psychiatry is bright, even scintillating'. He maintains that 'psychiatric practice will be transformed into a clinical neuroscience that will heal the mind by replacing the brain'. In particular, he mentions new technologies, including 'cranial electrical stimulation (CES), deep brain stimulation (DBS), epidural cortical stimulation (ECS), focused ultrasound (FUS), low-field magnetic stimulation (LFMS), magnetic seizure therapy (MST), near infrared light therapy (NIR), and transcranial direct current stimulation (TDCS)'. ${ }^{42}$ What this will mean for patients is still unknown.

\section{Conclusion}

This chapter began with the patient Robairt Clough's ditty, published in the 1972 Christmas edition of the patients' magazine of Holywell Psychiatric Hospital in Antrim:

\section{Little drops of medicine, \\ Little coloured pills, \\ Cure us of all ailments, \\ Cure us of all ills.}

A year after Robairt Clough wrote these words, the Christmas edition of the magazine was to be the last edition. In-patient numbers at the Holywell Psychiatric Hospital were in decline. Faculties were 'generally cramped', occupational therapy was 'substandard' and the entire health service was being restructured. ${ }^{43}$ With deinstitutionalisation, 'communities of suffering' moved elsewhere; diagnostic categories expanded dramatically with the growth of the therapeutic state; anti-psychiatry morphed into patient activism; and those 'little coloured pills' continued to be popped into the open mouths of patients like Robairt Clough who waited for 'the day we're free'.

\section{Summary Key Points}

- This chapter draws attention to social encounters between medical professionals and patients.

- Deinstitutionalisation, changes in diagnostic nomenclature, anti-psychiatry, patients' movements, evidence-based medicine and advances of psychopharmacology, neurochemistry and neurobiology are among the main encounters between professionals and patients from the 1960s to the 2010s. 
- Discipline, power and social construction have been prominent in the policy and politics of psychiatry.

- Deinstitutionalisation is perhaps the most important social experiment of the last century.

- The mental health needs of older people, homosexuality and consent are among the major themes underlined during the fifty years under consideration.

\section{Notes}

1. R. Clough, Holywell Rhymes. Speedwell (1972) 22: 29.

2. V. Hess and B. Majerus, Writing the history of psychiatry in the 20th century. History of Psychiatry (2011) 22: 139-45, 140; R. Porter, Patients and Practitioners: Lay Perceptions of Medicine in Pre-Industrial Society. Cambridge: Cambridge University Press, 1985.

3. J. Bourke, The Story of Pain: From Prayer to Painkillers. Oxford: Oxford University Press, 2016.

4. J. E. Powell, 'Enoch Powell's Water Tower Speech 1961', www.studymore.org.uk/xpowell.htm.

5. B. Cooper, British psychiatry and its discontents. Journal of the Royal Society of Medicine (2010) 103: 397-402, 394.

6. J. Turner, R. Hayward, K. Angel et al., The history of mental health services in modern England: Practitioner memories and the direction of future research. Medical History (2015) 59: 599-624, 604.

7. V. Long, Heading up a blind alley? Scottish psychiatric hospitals in the era of deinstitutionalization. History of Psychiatry (2017) 28: 115-28, 117.

8. D. Double, The limits of psychiatry. The British Medical Journal (April 2002) 324: 900-4, 901.

9. I. Shaw, A short history of mental health. In I. Shaw, H. Middleton and J. Cohen, eds, Understanding Treatment without Consent: An Analysis of the Work of the Mental Health Act Commission, 3-12. Aldershot: Ashgate, 2007, p. 8.

10. R. Porter, Two cheers for psychiatry!: The social history of mental disorder in twentieth century Britain. In H. Freeman and G. E. Berrios, eds, 150 Years of British Psychiatry: Volume 2: The Aftermath, 383-406. London, Athlone Press, 1996.

11. BBC, Dobson outlines mental health plans, BBC News, 29 July 1998, http://news.bbc.co.uk/1/hi/health/141 651.stm.

12. C. Hilton, Psychiatrists, mental health provision, and 'senile dementia' in England, 1940s-1979. History of Psychiatry (2015) 26: 182-99, 182.

13. Ibid., 185.

14. Psychiatric Disorders in the Aged: Report of the Symposium Held by the World Psychiatric Association at the Royal College of Physicians, London, September 28th-30th, 1965, Manchester: Geigy, 1965.

15. Hilton, Psychiatrists, mental health provision, and 'senile dementia' in England, 185.

16. Ibid., 190.

17. Ibid., 183. See also The Oral History of Geriatrics as a Medical Specialty Collection, Oral History Collections, British Library, BL C512/39/01.

18. J. A. Whitehead, Psychiatric Disorders in Old Age: A Handbook for the Clinical Team. Aylesbury: Harvey Miller and Medcalf, 1974, p. 5.

19. D. G. Cooper, Psychiatry and Anti-Psychiatry. London: Tavistock Publications, 1967, p. x.

20. O. Wall, The British Anti-Psychiatrists: From Institutional Psychiatry to the Counter-Culture, 1960-1971.

London: Routledge, 2018. 
21. R. D. Laing, The Voice of Experience: Experience, Science and Psychiatry. London: Allen Lang, 1982.

22. M. E. Staub, Madness Is Civilization: When the Diagnosis Was Social, 1948-1980. Chicago: University of Chicago Press, 2011.

23. M. Barnes and J. Berke, Mary Barnes: Two Accounts of a Journey Through Madness. Harmondsworth: Penguin Books, 1973.

24. A. Scull, Mental patients and the community: A critical note. International Journal of Law and Psychiatry (1986) 9: 383-92.

25. G. Smith, A. Bartlett and M. King, Treatments of homosexuality since the 1950s - an oral history: The experience of patients. The British Medical Journal (February 2004) 328: 427-29, 428.

26. Ibid.

27. Medical Defence Union, Consent to Treatment. London: Medical Defence Union, 1971.

28. P. Campbell, From little acorns: The mental health service user movement. In A. Bell and P. Lindley, eds, Beyond the Water Towers: The Unfinished Revolution in Mental Health, 73-82. London: Sainsbury Centre for Mental Health, 2005.

29. M. Waltz, Autism: A Social and Medical History. Basingstoke: Palgrave Macmillan, 2013.

30. N. Crossley, Transforming the mental health field: The early history of the National Association for Mental Health. Sociology of Health and Illness (1998) 20: 458-88.

31. Waltz, Autism.

32. A. Mold, Making the Patient-Consumer: Patient Organisations and Health Consumerism in Britain. Manchester: Manchester University Press, 2015.

33. Ibid., p. 204.

34. M. S. Micale, On the 'disappearance' of hysteria: A study in the clinical deconstruction of a diagnosis. ISIS (1993) 84: 496-526.

35. British Medical Journal, The search for a psychiatric Esperanto. British Medical Journal (1976) 2: 600-1.

36. G. Eghigian, Deinstitutionalizing the history of contemporary psychiatry. History of Psychiatry (2011) 22: 201-14.

37. M. V. Seeman, Forty-five years of schizophrenia: Personal reflections. History of Psychiatry (2006) 17: 363-73.

38. A. Donald, The Wal-Marting of American psychiatry: An ethnography of psychiatric practice in the late-twentieth century. Culture, Medicine, and Psychiatry (December 2001) 25: 467-72.

39. P. Fennell, Treatment without Consent: Law, Psychiatry, and the Treatment of Mentally Disordered People Since 1845. London: Routledge, 1996, p. 156.

40. Quoted in ibid., p. 158.

41. M. S. Micale, The ten most important changes in psychiatry since World War II. History of Psychiatry (2014): 25: 485-91; D. Healy, The Creation of Psychopharmacology. Cambridge, MA: Harvard University Press, 2002.

42. H. A. Nasrallah, Transformative advances unfolding in psychiatry. Current Psychiatry (2019) 18: 10-12.

43. P. Prior and G. McClelland, Through the lens of the hospital magazine: Downshire and Holywell psychiatric hospitals in the 1960s and 1970s. History of Psychiatry (2013) 24: 399-414. 